\title{
A Commercially Available Skin Care Lotion with a pH of 4.5 and $10 \%$ Urea Improves Skin Surface pH, Stratum Corneum Hydration and Epidermal Barrier Function in Subjects with Dry Skin and Atopic Diathesis
}

\author{
Jürgen Blaak1, Christiane Theiss ${ }^{1}$, Marina Schleißinger ${ }^{1}$, Isabel Simon1, Nanna Y. Schürer², \\ Peter Staib1* \\ ${ }^{1}$ Department of Research \& Development and Regulatory Affairs, Kneipp GmbH, Würzburg, Germany \\ ${ }^{2}$ Department of Dermatology, Environmental Medicine and Health Theory, University of Osnabrück, Osnabrück, Germany \\ Email: *peter.staib@kneipp.de
}

How to cite this paper: Blaak, J., Theiss, C., Schleißinger, M., Simon, I., Schürer, N.Y. and Staib, P. (2020) A Commercially Available Skin Care Lotion with a $\mathrm{pH}$ of 4.5 and $10 \%$ Urea Improves Skin Surface pH, Stratum Corneum Hydration and Epidermal Barrier Function in Subjects with Dry Skin and Atopic Diathesis. Journal of Cosmetics, Dermatological Sciences and Applications, 10, 116-133.

https://doi.org/10.4236/jcdsa.2020.103014

Received: July 16, 2020

Accepted: September 7, 2020

Published: September 10, 2020

Copyright ( 2020 by author(s) and Scientific Research Publishing Inc. This work is licensed under the Creative Commons Attribution International License (CC BY 4.0).

http://creativecommons.org/licenses/by/4.0/

(c) (i) Open Access

\begin{abstract}
OBJECTIVE: The physiological skin surface $\mathrm{pH}$ is crucial for several epidermal barrier functions, like stratum corneum integrity, cohesion and restoration. Alterations of the "normal" acidic nature of the skin surface have been shown to correlate with specific skin conditions like aged or inflamed skin and are leading to impaired skin barrier function and formation. It is previously demonstrated that topical acidification in atopic dermatitis improves stratum corneum function, skin barrier structure and clinical signs in dermatitis. Against this background, we examined the impact of a slightly acidic skin care product containing urea on stratum corneum hydration, skin surface $\mathrm{pH}$ and epidermal barrier function in subjects with dry skin and atopic diathesis. METHODS: Stratum corneum hydration, skin surface $\mathrm{pH}$ and transepidermal water loss were biophysically measured before and after a 4-week treatment period with the test product ( $\mathrm{pH} 4.5,10 \%$ urea) compared to the reference product in 25 volunteers. In addition, dynamic epidermal barrier parameters like stratum corneum integrity, cohesion and recovery were investigated by using a previously described tape stripping approach. RESULTS: It was shown that the test product ( $\mathrm{pH} 4.5,10 \%$ urea) significantly elevated stratum corneum hydration and improved the acidic nature of the skin surface by lowering the skin surface $\mathrm{pH}$ to a greater extent compared to the reference product. After the 4-week treatment period a significant faster barrier restoration was detected on the test site treated with the test product compared to the reference product. Moreover, the test product strengthens
\end{abstract}


the skin barrier integrity and cohesion. CONCLUSION: The present marketed skin care lotion was shown to increase epidermal barrier function after 4 weeks of application. Balancing and controlling the skin surface $\mathrm{pH}$ in subjects with dry and atopic-prone skin by application of the herein tested $\mathrm{o} / \mathrm{w}$ emulsion with a given $\mathrm{pH}$ of 4.5 , in combination with a $10 \%$ urea content seems to be effective and beneficial. The results are important for the formulation of topical products for dry and atopic-prone skin.

\section{Keywords}

Skin Barrier, Skin Physiology, Acidic Formulation, Urea, Atopic Skin

\section{Introduction}

The skin, or more precisely the epidermal permeability barrier (EPB), is the most important blockade to protect the human body from external influences [1] [2] [3]. The main part of the EPB is formed by the stratum corneum (SC). This outer layer of the skin consists of corneocytes embedded in a highly organized lipid matrix and it is important for a proper skin permeability function [4] [5]. The SC protects the body from external influences, e.g. allergens and microorganisms, and in addition prevents the body from an excessive transepidermal water loss (TEWL) [6] [7]. Besides the given skin barrier structure of proteins and lipids, the skin surface $\mathrm{pH}$ (ss-pH) and the individual cutaneous microbiome are important for an adequate EPB function [8] [9] [10] [11] [12]. Disturbances of these factors can trigger malfunction of the EPB function and moisture regulation, i.e. very dry and scaly skin, or even worse, skin diseases such as atopic dermatitis (AD) [13] [14] which is a common, multifactorial inflammatory disease associated with very dry, rough, itchy and inflamed skin [15].

The understanding of the ss- $\mathrm{pH}$ has broadened in the last 20 years, and it is well documented that the ss-pH is crucial for several epidermal functions such as integrity, cohesion and recovery of the SC [16]. The physiological ("normal") $\mathrm{pH}$ of the skin surface in most body areas is defined as just below 5.0 [17] [18], and was first described with the term "acid mantle" by Schade and Marchionini in 1928 [19]. Alterations of the normal ss-pH have been shown to correlate with specific conditions like aged skin [20] [21] [22] [23] [24] or inflamed skin, such as $\mathrm{AD}$ [13] [14] [25]. For both skin conditions, an ss-pH above 5.0 is described and associated to symptoms like rough and dry skin, itching, and an increased rate of skin infections [26] [27], which is partly linked to the crucial role of the ss-pH in the regulation of SC integrity, cohesion (converse of desquamation) and restoration [28]. The continuous desquamation depends on the activity of serine proteases [29], especially kallikrein 5 (KLK5) and kallikrein-7 (KLK7) [30]. It is shown that both proteases exhibit a neutral pH optimum [31]. By the physiological slightly acidic ss-pH the activity of KLK5 and KLK7 is regulated and thereby desquamation is balanced [32]. Furthermore, EPB homeostasis and 
recovery also depend on ss-pH. It is shown that treatment of artificially disturbed skin with neutral $\mathrm{pH}$ buffer decreases SC recovery [33]. This delayed repair is related to the inhibition of the two lipid-processing enzymes acidic sphingomyelinase (aSMase) and $\beta$-glucocerebrosidase (BGC), which offer a slightly acidic $\mathrm{pH}$ optimum [34]. Both hydrolases are key factors in EPB formation and restoration and transfer polar lipids to the non-polar barrier lipid matrix [35]. Based on the link between ss-pH and corneophysiology, any alteration of the acidic ss-pH 1) increases the activity of KLK5 and KLK7, 2) and inhibits the activity of the lipid-processing enzymes BGC and aSMase. This corneal dysfunction results in an elevated degradation of corneodesmosomes and insufficient formation of the lamellar lipid bilayers [32].

To overcome negative effects of an elevated ss-pH, e.g. in aged skin, several controlled trials were initiated to investigate the effect of acidic skin care products on ss-pH regulation and thereby on EPB function, especially in aged skin [23] [36] [37] [38] [39] [40]. These research activities have variously shown that the application of slightly acidic formulations (oil-in-water, water-in-oil) with a given $\mathrm{pH}$ of 4.0 can directly shift the elevated ss- $\mathrm{pH}$ in elderly skin back to a physiological level and thus, improve EPB integrity, recovery and structure of the SC lipid matrix. Apart from these investigations on aged skin, studies were conducted to reveal the relation between ss-pH, EPB function and inflammation in $\mathrm{AD}$. It was shown in atopic mice, that maintaining physiological ss- $\mathrm{pH}$ by topically applied lactobionic acid enhances EPB function, including normalization of antimicrobial peptide expression and decrease in cytokine generation [41]. In addition, SC recovery after experimental $\mathrm{pH}$ neutralization is delayed and skin inflammation and dermatitis aggravated [42]. Furthermore, Lee et al. [43] monitored long-term effects of exogenous SC acidification in a specific atopic murine model accompanied by an asthma-like respiratory allergy (induced by oxazolone followed by inhalation of house dust mite; "atopic march animal model"). It was demonstrated that application of an acidic cream ( $\mathrm{pH}$ 2.8) minimizes atopic skin lesions and additionally inhibits the respiratory inflammation. Another study by Jang et al. [44] investigated the relation between $\mathrm{pH}$ and the pathogenesis in an $\mathrm{AD}$ mice model. It was shown that experimental elevation of ss-pH leads to AD-like dermatitis and EPB dysfunction. In contrast, acidification of severe eczematous lesions results in reduced TEWL, ss-pH, KLK5 activity and dermal inflammation. Against this background, balancing and controlling the ss- $\mathrm{pH}$ by formulations with reduced $\mathrm{pH}$ might be a beneficial skin care strategy to overcome pathological $\mathrm{pH}$ variations and $\mathrm{EPB}$ dysfunction in $\mathrm{AD}$ [45] [46].

Considering the comprehensively studied impact of targeted SC acidification with cosmetic emulsions in elderly and the first corresponding study results in atopic skin conditions, the present study was conducted to investigate the effectiveness of a commercially available skin care lotion, developed with a slightly acidic $\mathrm{pH}$ of 4.5 and $10 \%$ urea in subjects with dry skin and atopic diathesis. Urea is widely used in dermo-cosmetic products for dry skin conditions and a 
physiological compound of the natural moisturizing factor of the epidermis and described as hydrating and barrier-enhancing active [47]. Additionally, it is commonly accepted that urea shows a broad effectiveness in the field of dermatology and cosmetics, especially to support EPB processes and function [48] [49] [50] [51].

Herewith, we posed the question whether the scientifically described positive effects of a slightly acidic product $\mathrm{pH}$ [52] in combination with a scientifically relevant urea content [47] generate positive effects on SC hydration, ss-pH and EPB function in subjects with xerotic and atopic skin.

\section{Methods and Materials}

\subsection{Study Panel Criteria}

25 volunteers ( 20 female, 5 male), aged between 22 and 69 years (mean $42.2 \pm$ 16.8 SD) participated in the present study. The data from all these persons were included in the statistical analysis. This single center, prospective study was conducted in compliance with the principles of the Declaration of Helsinki to fulfill ethical standards. All study participants were informed in detail about the aims, risks and benefits of the study and agreed to participate. Participation was voluntary, and each participant had enough time to consider participation.

The study was open to subjects with an initial ss-pH above 5.0 on the test sites (volar forearm) and an atopic diathesis and/or very dry skin. Potential volunteers excluded from study participation had a SCORAD over 25, an acute exacerbation of atopic eczema and/or pathological skin changes on the forearm. The participants described the skin on the forearm as "very dry" $(\mathrm{n}=3)$, "dry" $(\mathrm{n}=14)$, or "normal" $(\mathrm{n}=8)$ and the skin condition on the body was described as "very dry" $(\mathrm{n}=4)$, "dry" $(\mathrm{n}=18)$, or "normal" $(\mathrm{n}=3)$. A total of 18 subjects reported atopic diathesis and 8 of them suffered from atopic dermatitis. In addition, 20 volunteers stated that they generally had sensitive skin.

Furthermore, the test sites were not allowed to get in contact with skin cleansing or skin care products 24 hours prior to the examination. During examination contact of the test sites with water and/or skin cleansing and skin care products was avoided as well as sauna visits and sports were not allowed.

\subsection{Test Products}

The test product $\mathrm{A}$ ( $\mathrm{pH} 4.5,10 \%$ urea), a commercially available skin care lotion, and the reference product $\mathrm{B}$ ( $\mathrm{pH} 6.5,0 \%$ urea), developed for the present study as control condition and not marketed, were applied to the allocated test areas. The reference test sample was chosen for different reasons. First, it was developed for this trial by the present study sponsor with a given $\mathrm{pH} 6.5$, which nearly reflects the $\mathrm{pH}$ value of several in the market existing topical formulations [53]. Moreover, it was formulated without urea and with a different lipid phase to detect the impact of these defined differences. Finally, a reference test sample was chosen as control condition instead of an "untreated" control site. The in- 
gredients (INCI name) and characteristics of the product A (Kneipp ${ }^{\circledR}$ Evening Primrose Skin Care) and the product $B$ are shown in Table 1. The allocation of both products to the forearm insides was randomized.

\subsection{Functional Assessment}

The SC hydration (arbitrary unit, a.u.) was measured with a Corneometer ${ }^{\circledR} \mathrm{CM}$ 825 (Courage \& Khazaka Electronic GmbH, Cologne, Germany) and EPB function was determined by measuring the TEWL $\left(\mathrm{g} / \mathrm{m}^{2} / \mathrm{h}\right)$ with a Tewameter ${ }^{\circledR} \mathrm{TM} 300$ (Courage \& Khazaka, Cologne, Germany). Furthermore, ss-pH was measured with a Skin-pH-Meter ${ }^{\circledR}$ PH905 (Courage \& Khazaka, Cologne, Germany).

The biophysical evaluation of the EPB function included: SC cohesion, SC integrity and SC recovery as previously utilized [36]. To evaluate the SC cohesion 10 sequential tape stripping on the volar forearm were performed, for which D-Squames (D-Squame Standard, CuDerm Corp., Dallas, Tex., USA) were employed. The amount of protein per D-Squame was determined by optical density measurement at a wavelength of $850 \mathrm{~nm}$ using infrared densitometry (SquameScanTM 850A, Heiland Electronic, Wetzlar, Germany). To evaluate SC integrity, the first 10 strips by D-Squames were followed by additional stripping with Blenderm ${ }^{\mathrm{TM}}$ Surgical Tape (3M Health Care, Neuss, Germany) to obtain a 3-fold increased TEWL (compared to baseline TEWL), which was interpreted as EPB perturbation. SC integrity was expressed as the number of tape stripping required to increase the TEWL by 3 -fold. TEWL measurements after perturbation reflected the SC recovery rate. To get a faster skin barrier breakdown the Blenderm $^{\text {TM }}$ Surgical Tape was used after 10 strips with D-Squames. Moreover, the tape stripping procedure was performed by one qualified and experienced technician, and thereby standardized.

Table 1. Composition and specifications of the test product $\mathrm{A}$ and the reference product B.

\begin{tabular}{|c|c|}
\hline Product code & Ingredients \\
\hline $\begin{array}{c}\text { Product A } \\
\text { (Internal No. NHH081) }\end{array}$ & $\begin{array}{l}\text { Aqua, Urea, Glycerin, Prunus Amygdalus Dulcis Oil, Oenothera Biennis } \\
\text { Oil, Tocopheryl Acetate, Cetearyl Alcohol, Panthenol, Glyceryl Stearate } \\
\text { SE, Sodium Lactate, Phytosterols, Bisabolol, Rosmarinus Officinalis Leaf } \\
\text { Extract, Citronellol, Benzyl Salicylate, Limonene, Geraniol, Linalool, } \\
\text { Benzyl Alcohol, p-Anisic Acid, Parfum, Caprylyl Glycol, Lactic Acid, } \\
\text { Sorbitan Oleate, Sodium Stearoyl Glutamate, Glycine Soja Oil, Ascorbyl } \\
\text { Palmitate, Xanthan Gum, Triacetin, Tocopherol } \\
\text { pH value: } 4.5 \pm 0.1 \\
\text { Content of urea [\%]: } 10.0\end{array}$ \\
\hline $\begin{array}{c}\text { Product B } \\
\text { (Internal No. GVB154) }\end{array}$ & $\begin{array}{l}\text { Aqua, Caprylic/Capric Triglyceride, Glycerin, Helianthus Annuus Seed } \\
\text { Oil, Cetearyl Alcohol, Glyceryl Stearate Citrate, p-Anisic Acid, Caprylyl } \\
\text { Glycol, Xanthan Gum, Glyceryl Caprylate, Acrylates/C10-30 Alkyl } \\
\text { Acrylate Crosspolymer, Sodium Hydroxide, Glycine Soja Oil, Tocopherol } \\
\text { pH value: } 6.5 \pm 0.1 \\
\text { Content of urea [\%]: } 0.0\end{array}$ \\
\hline
\end{tabular}




\subsection{Experimental Designs}

At the beginning of the study, the 25 subjects introduced themselves on two consecutive days. The test areas (volar forearms) were preconditioned, i.e. no skin care products were applied to them 24 hours before the start of the study and they could not be washed 12 hours before the measurement. After an acclimatization time of 30 minutes, the measurements were carried out according to the international recommendations for skin physiological measurement in the field of cosmetics [54] [55] [56]. As shown in Table 2, the experimental setting was structured in two phases: 1) before treatment and 2) after 4-week treatment, and both of these phases were subdivided in baseline: $\mathrm{tb}(0)$ and $\mathrm{t} 4 \mathrm{w}(0)$; post tape stripping: $\mathrm{tb}\left(0^{*}\right)$ and $\mathrm{t} 4 \mathrm{w}\left(0^{*}\right)$; after 8 hours measurement: $\mathrm{tb}(8)$ and $\mathrm{t} 4 \mathrm{w}(8)$; and 24 hours measurement: $\mathrm{tb}(24)$ and $\mathrm{t} 4 \mathrm{w}(24)$.

At the first examination day baseline values for the SC hydration, TEWL and ss-pH were determined, including SC integrity and cohesion by tape stripping. TEWL was also determined directly, i.e. post tape stripping to control EPB perturbation, 8 and 24 hours after the experimental barrier damage to reflect the regeneration over 24 hours. All measurements were completely repeated after the 4-week (Table 2) treatment. The subject returned to the study site for measurements 10 to 16 hours after the last product application.

Subsequently, all volunteers randomly received the test product $\mathrm{A}$ and the

Table 2. The study schedule was structured in two phases: before and after 4-week treatment. SC, stratum corneum; ss-pH, skin surface $\mathrm{pH}$; TEWL, transepidermal water loss.

\begin{tabular}{|c|c|c|c|c|}
\hline \multirow{2}{*}{ Before treatment } & baseline & post tape stripping & after $8 \mathrm{~h}$ & after $24 \mathrm{~h}$ \\
\hline & $\mathrm{tb}(0)$ & $\operatorname{tb}\left(0^{*}\right)$ & $\mathrm{tb}(8)$ & $\mathrm{tb}(24)$ \\
\hline Informed consent & $\mathrm{x}$ & & & \\
\hline In-/exclusion criteria & $\mathrm{x}$ & & & \\
\hline SC hydration, ss-pH & $\mathrm{x}$ & & & \\
\hline TEWL & $\mathrm{x}$ & $\mathrm{x}$ & $\mathrm{x}$ & $\mathrm{x}$ \\
\hline Tape stripping & $\mathrm{x}$ & & & \\
\hline SC integrity & & $\mathrm{x}$ & & \\
\hline SC cohesion & & $\mathrm{x}$ & & \\
\hline SC recovery & & & $\mathrm{x}$ & $\mathrm{x}$ \\
\hline \multirow{2}{*}{ After treatment } & baseline & post tape stripping & after $8 \mathrm{~h}$ & after $24 \mathrm{~h}$ \\
\hline & $\mathrm{t} 4 \mathrm{w}(0)$ & $t 4 w\left(0^{*}\right)$ & $\mathrm{t} 4 \mathrm{w}(8)$ & $\mathrm{t} 4 \mathrm{w}(24)$ \\
\hline SC hydration, ss-pH & $\mathrm{x}$ & & & \\
\hline TEWL & $\mathrm{x}$ & $\mathrm{x}$ & $\mathrm{x}$ & $\mathrm{x}$ \\
\hline Tape stripping & $\mathrm{x}$ & & & \\
\hline SC integrity & & $\mathrm{x}$ & & \\
\hline SC cohesion & & $\mathrm{x}$ & & \\
\hline SC recovery & & & $\mathrm{x}$ & $\mathrm{x}$ \\
\hline
\end{tabular}


reference product $\mathrm{B}$. The formulations were applied to the left or right forearm in the morning and evening for a period of 4 weeks. To avoid confusions and mistakes, the products were labelled "L" and "R" (left/right), respectively. Half of the subjects applied product $\mathrm{A}$ to the left forearm and product $\mathrm{B}$ to the right forearm and the other half applied the products vice versa. The ss-pH measurement of both forearms was performed 2 weeks after the basic data were collected. After a 4-week application period, the skin physiological parameters described above were measured again and compared with the basic data. The assessment was carried out at room temperature $\left(19.5^{\circ} \mathrm{C} \pm 0.5^{\circ} \mathrm{C}\right)$ and a relative humidity of $48 \% \pm 2 \%$ in October and November 2018 .

\subsection{Statistical Analysis}

Statistical analysis was performed using SPSS software version 25.0 for Macintosh (IBM Corp., Armonk, NY, USA) and data evaluation included all measured values. The significance level was set at $p=0.05$, therefore $p$-values $<0.05$ are considered significant. The obtained data were checked for normal distribution before statistical analysis and then analyzed with the Wilcoxon test (non-parametric, paired data) or Mann-Whitney-U-Test (non-parametric, unpaired data).

\section{Results}

At the baseline situation ss-pH ( $\mathrm{p}=0.532)$, SC hydration $(\mathrm{p}=0.823)$ and TEWL $(\mathrm{p}=0.734)$ of selected test areas were comparable, i.e. no significant differences were observed. After a 4-week treatment regimen with product A or B the ss-pH was significantly decreased only in the allocated product $\mathrm{A}$ treated test area $(-0.560$, from 5.79 to $5.23, \mathrm{p}=0.000)$, while the $\mathrm{ss}-\mathrm{pH}$ in the product $\mathrm{B}$ treated test area remained unchanged $(-0.036$, from 5.74 to $5.70, p=0.660)$. Furthermore, after the 4-weeks treatment regimen statistical analyses revealed significant $(\mathrm{p}=0.000)$ differences between the product $\mathrm{A}$ and $\mathrm{B}$ treated test areas (Figure 1).

After the 4-week treatment regimen with either product A or B the SC hydration increased significantly $(p=0.000)$. SC hydration increased from 39.68 to 51.30 in the product $\mathrm{A}$ treated test area and from 39.34 to 46.52 in the product $\mathrm{B}$ treated test area, respectively (Figure 2). However, after the 4-weeks treatment regimen statistical analyses revealed significant differences of SC hydration when the two test areas were compared $(\mathrm{p}=0.021)$.

Before the 4-week treatment regimen $20.16 \pm 7.01$ tape stripping in the product A treated area were needed compared to $19.44 \pm 6.16$ tape stripping in the product B treated area to obtain a 3-fold increased TEWL, i.e. to perturb EPB structure (Table 3). Statistical analyses revealed no differences when the two test areas were compared at baseline $(\mathrm{p}=0.572)$. In contrast to baseline, the SC integrity in product $A$ treated area improved significantly $(p=0.000)$ after 4 -weeks of treatment as indicated by the higher number of tape stripping required to disturb the EPB function $(29.16 \pm 13.61)$. 


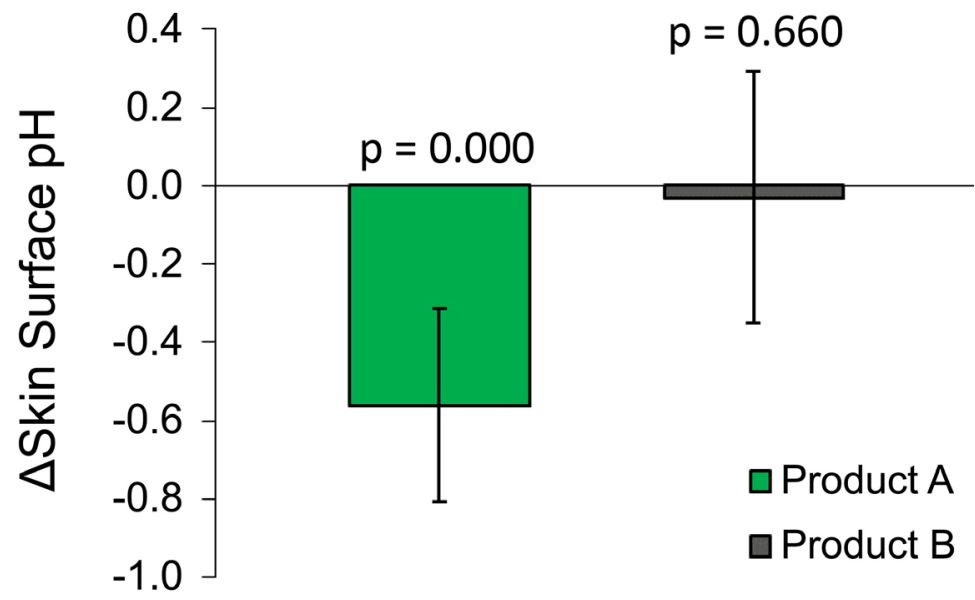

Figure 1. Changes in skin surface $\mathrm{pH}(\Delta)$ are indicated as the difference between the $\mathrm{pH}$ at two time points: $\mathrm{tb}(0)$ (before treatment) and $\mathrm{t} 4 \mathrm{w}(0)$ (after 4 weeks of treatment). Product A ( $\mathrm{pH} 4.5,10 \%$ urea) compared to product B ( $\mathrm{pH} 6.5,0 \%$ urea), with significant differences to baseline for test product $\mathrm{A}$. The $\mathrm{p}$-values $<0.05$ are considered significant.

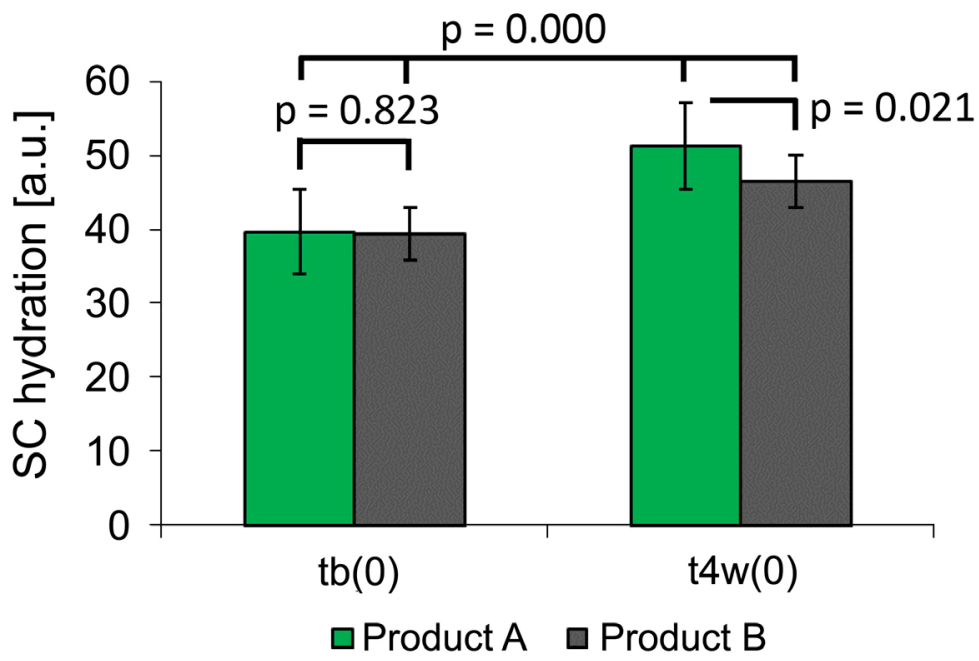

Figure 2. SC hydration baseline values before treatment $(\mathrm{tb}(0))$ and baseline values after 4-week treatment $(\mathrm{t} 4 \mathrm{w}(0))$ with product $\mathrm{A}(\mathrm{pH} 4.5,10 \%$ urea) compared to product $\mathrm{B}$ ( $\mathrm{pH} 6.5,0 \%$ urea), with significant differences after treatment. The p-values $<0.05$ are considered significant. SC, stratum corneum; a.u., arbitrary unit.

Table 3. Number of tape stripping to obtain a 3-fold increased TEWL, interpreted as epidermal barrier integrity. Data presented for prior $(\mathrm{tb})$ and after a 4 -week treatment $(\mathrm{t} 4 \mathrm{w})$ regimen with either product $\mathrm{A}$ ( $\mathrm{pH} 4.5,10 \%$ urea) compared to product $\mathrm{B}$ ( $\mathrm{pH}$ $6.5,0 \%$ urea). The $\mathrm{p}$-values $<0.05$ (in bold) are considered significant.

\begin{tabular}{cccccc}
\hline & \multicolumn{3}{c}{ Product A } & \multicolumn{2}{c}{ Product B } \\
\cline { 2 - 6 } & tb & t4w & tb & t4w \\
\hline $\begin{array}{c}\text { Number of tape strippings [Mean } \pm \text { SD] } \\
\text { p-value [Wilcoxon-Test] }\end{array}$ & $20.16 \pm 7.01$ & & $29.16 \pm 13.61$ & $19.44 \pm 6.16$ & $20.52 \pm 6.70$ \\
( & & 0.000 & & 0.050 & \\
\hline
\end{tabular}

However, the number of tape stripping (10 times D-Squames and $X$ times Blenderm ${ }^{\mathrm{TM}}$ Surgical Tape) remained unchanged in the product $\mathrm{B}$ treated area 
(19.44 \pm 6.16 compared to $20.52 \pm 6.70 ; \mathrm{p}=0.050)$. Upon comparison of both treatment areas after the 4 -weeks treatment regimen $(29.16 \pm 13.61$ compared to $20.52 \pm 6.70)$, significant differences $(\mathrm{p}=0.000)$ in SC integrity were also revealed (Table 3 ). Concerning the recovery rate, $24 \mathrm{~h}$ after barrier perturbation via tape stripping the TEWL was significantly reduced in both allocated test areas prior to and after the 4 -week treatment regimen ( $p=0.000$; Figure 3 ), but with significant differences between the test sites for the treatment regimen, i.e. product A compared to product B for the $8 \mathrm{~h}$ and the $24 \mathrm{~h}$ measurement: $44 \mathrm{w}(8)$ : $\mathrm{p}=0.017 ; \mathrm{t} 4 \mathrm{w}(24): \mathrm{p}=0.018$.

The amount of protein removed per strip is reflected by the percentage absorbance. The lower the absorbance, the less protein (i.e. corneocytes) sticks to the D-Squame and the better SC cohesion is. Prior to treatment no significant differences in the two treatment areas were shown for tape $1(\mathrm{p}=0.445)$, tape 5 $(\mathrm{p}=0.885)$ and tape $10(\mathrm{p}=0.695)$, that means SC cohesion was comparable at baseline (Figure 4). After the 4-week treatment regimen the D-Squame absorbance was significantly lower in the product $\mathrm{A}$ treated area compared to product B treated area: for tape 1: $\mathrm{p}=0.000$, tape 5: $\mathrm{p}=0.01$ and tape 10: $\mathrm{p}=0.000$.

However, both treatment modalities revealed a significant decrease of absorbance. Product A: tape 1: $\mathrm{p}=0.000$, tape 5: $\mathrm{p}=0.000$, tape 10: $\mathrm{p}=0.000$. Product B: tape 1: $p=0.003$, tape $5: p=0.002$, tape $10: p=0.006$. Nevertheless, values

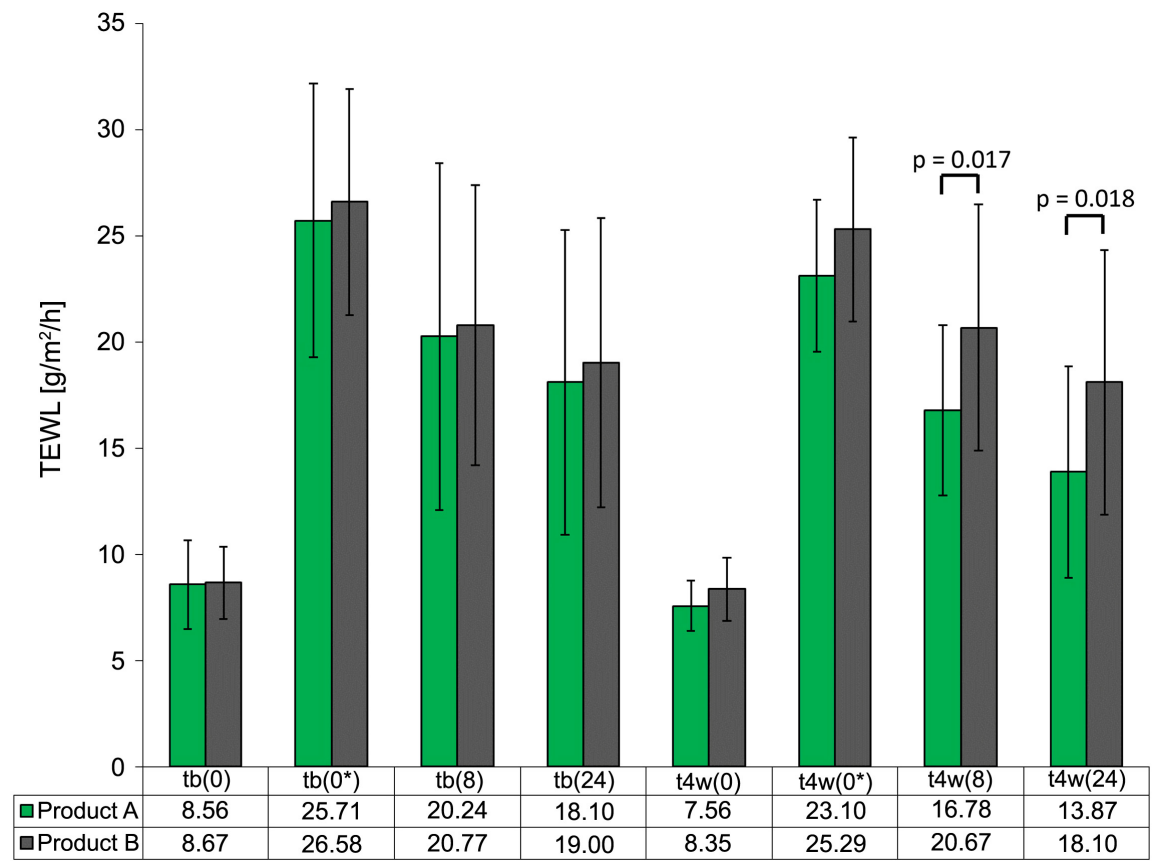

Figure 3. TEWL $\left[\mathrm{g} / \mathrm{m}^{2} / \mathrm{h}\right.$ ] measurement along the complete experimental period. Baseline TEWL before $(\mathrm{tb})$ and after treatment $(\mathrm{t} 4 \mathrm{w})$ at different time points: baseline $(\mathrm{tb}(0)$, $\mathrm{t} 4 \mathrm{w}(0))$, post tape stripping $\left(\mathrm{tb}\left(0^{\star}\right), \mathrm{t} 4 \mathrm{w}\left(0^{*}\right)\right), 8 \mathrm{~h}$ after tape stripping $(\mathrm{tb}(8), \mathrm{t} 4 \mathrm{w}(8))$, and $24 \mathrm{~h}(\mathrm{tb}(24), \mathrm{t} 4 \mathrm{w}(24))$ after tape stripping. SC recovery (decrease in TEWL) is shown for product $\mathrm{A}(\mathrm{pH} 4.5,10 \%$ urea) compared to product $\mathrm{B}$ ( $\mathrm{pH} 6.5,0 \%$ urea) treated areas, with significant differences after 4 -week treatment. The $\mathrm{p}$-values $<0.05$ are considered significant. TEWL, transepidermal water loss. 


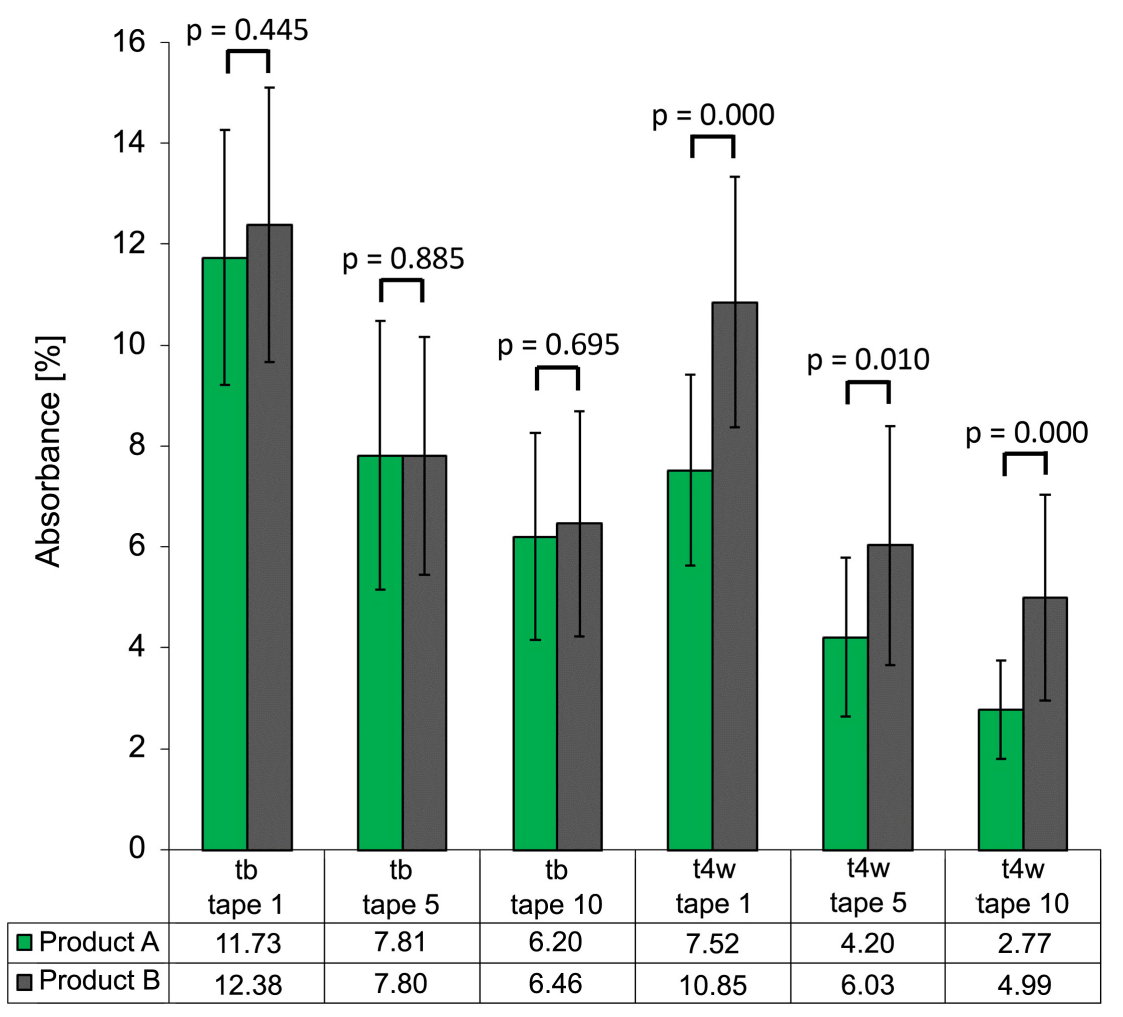

Figure 4. Absorbance (\%) by optical density measurement of D-Squames (wavelength of $850 \mathrm{~nm})$. Values of tape no. 1, 5, and 10 prior (tb) and after 4-week treatment $(\mathrm{t} 4 \mathrm{w})$ are presented for product $\mathrm{A}$ ( $\mathrm{pH} 4.5,10 \%$ urea) compared to product $\mathrm{B}$ ( $\mathrm{pH} 6.5,0 \%$ urea), including significant differences after 4 -week treatment. The p-values $<0.05$ are considered significant.

were significantly lower in the product A treated area compared to the product B treated area.

Finally, the product treatment was well-tolerated, i.e. no adverse effects were reported by the volunteers and no skin reactions were observed by the dermatologist during the study period.

\section{Discussion}

For $\mathrm{AD}$ an elevated ss-pH is described, whereby $\mathrm{pH}$ differences between 0.1 and 0.9 units were demonstrated in atopic skin compared to healthy skin [46]. Besides the pathological changes in $\mathrm{pH}, \mathrm{SC}$ hydration is decreased, natural moisturizing factor synthesis is reduced [57] and as one consequence atopic skin is characterized by dry, rough and eczematous skin [58]. In addition, alterations in EPB structure and lipid matrix are described, especially in the content of ceramides [59] or in the intercellular lipid lamellae organization [60].

Based on these abnormalities in skin physiology and lipid structure, we asked the question, whether 1) acidification of the skin by a formulation with reduced $\mathrm{pH}$ and 2) hydrating the skin by a specific urea concentration combined in one $\mathrm{o} / \mathrm{w}$ emulsion can improve dry and atopic-prone skin. In recent years, a few studies investigating atopic murine skin were performed to evaluate the relation of 
ss-pH, EPB function and dermatitis. It was demonstrated, that maintaining normal ss-pH by topical application of lactobionic acid enhances EPB function, regulates antimicrobial peptide expression and reduces cytokine production in atopic mice [41]. Furthermore, Sakai et al. have shown that SC repair after experimental induced SC pH neutralization is decreased and skin inflammation enhanced in murine atopic skin [42]. Long-term effects of SC acidification were studied by Lee et al. [43], in an atopic march animal model. It was shown that topical application of a cream with a given $\mathrm{pH}$ of 2.8 reduces atopic skin lesions and beyond can block respiratory inflammation. In line with these results another recent study also investigated the interrelationship of $\mathrm{pH}$ and the pathogenesis of $\mathrm{AD}$ in mice [44]. It was discovered that increasing the ss- $\mathrm{pH}$ results in AD-like dermatitis and impaired EPB function. Vice versa, experimental acidification of severe eczematous lesions with lactobionic acid results in reduced ss-pH, TEWL, serine protease activity, i.e. the desquamation-processing enzyme KLK5, and minimizes dermatitis [45]. These study results are in line with several investigations on aged skin, where various studies have shown the benefit of slight acidification by skin care emulsions with a given $\mathrm{pH}$ of 4.0. Normalization of the enhanced ss-pH in the elderly to a physiological level was linked to improved SC integrity, recovery and lipid formation [23] [36] [37] [38] [39] [40]. Based on the results concerning $\mathrm{pH}$ and aged skin, it was recommended to balance and control ss-pH by exogenous acidification using skin care products with a $\mathrm{pH}$ of approximately 4.0, and thereby improving EPB function and maintaining skin health [36]. In the present work, the 4-week application of the test product A has significantly reduced the mean ss-pH from 5.8 to 5.2, that means decreased to a more physiological (healthy) level [17] [18], which was not achieved by the reference product B (Figure 1).

The physiological acidic ss-pH regulates various SC functions, such as integrity, cohesion and repair [1] [2] [3]. The continuous desquamation depends on the activity of serine proteases [29] and the healthy acidic ss-pH regulates the activity of KLK5 and KLK7 which balances desquamation and vice versa SC cohesion [32]. Furthermore, EPB homeostasis and recovery also depend on ss-pH [33] and are related to the regulation of two lipid-processing enzymes (aSMase, BGC), which both offer a slightly acidic pH optimum [34]. As recently reviewed by Denby and Cork [46] perturbation of the physiological ss-pH in atopic skin leads to reduced EPB homeostasis, suppressed antimicrobial defense and increased protease activity, that in turn results in inflammation and pruritus. Based on these described mechanisms, exogenous SC acidification and normalization of the ss-pH controls the activity of KLK5 and KLK7 and increases the activity of the lipid-processing enzymes BGC and aSMase, which in turn may lead to elevated SC integrity and cohesion and accelerated SC restoration in skin conditions with non-physiological $\mathrm{pH}$ changes [36]. Herein, the skin barrier disruption was obtained via repeated tape stripping and the indicator was a 3 -fold increased TEWL. The barrier regeneration is characterized by the decrease of TEWL over the first 24 hours (Figure 3). After 4 weeks of application a 
significant faster barrier regeneration was documented on the forearms treated with the slightly acidic product $\mathrm{A}$ than on the forearms treated with the near $\mathrm{pH}$ neutral product $\mathrm{B}$. The amount of tape strips necessary to reach the 3-fold increased TEWL was documented and reflects the SC integrity (Table 3 ). The more tape strips are needed to irritate the barrier, the more stable is the skin barrier. Only after application of product A significant more tape strips were needed to achieve a 3 -fold increased TEWL, so it is assumed that product A strengthens the skin's resistance, but not the reference product B. Regarding SC cohesion, i.e. the cohesion of corneocytes correlates with barrier integrity. The better the cohesion of the corneocytes, the lower the protein concentration in tape strips (Figure 4). The 4-week treatment with both products resulted in a significantly lower protein concentration on the strips but compared to product $B$ the protein concentration after application of product A was significantly lower. The herewith tested commercially available skin care product improves SC integrity, cohesion and recovery significant and therefore the relation between EPB function and topical management of the ss-pH seems to be verified in subjects with dry skin and atopic diathesis.

Apart from the enhanced ss-pH, atopic skin is characterized by reduced SC hydration and impaired SC lipid structure and composition [57] [58] [59] [60]. The correlation between skin barrier function and SC hydration is commonly accepted [61]. The higher the SC hydration, the more stable is the EPB function, and therefore in turn the lower SC hydration and the more unstable the EPB function. After 4-week treatment the SC hydration was increased with both applications. However, the SC hydration was significantly higher after application of product A compared to product B (Figure 2). Objective of the present work was to evaluate the effect of a marketed skin care product with a given $\mathrm{pH}$ of 4.5 and a urea concentration of $10 \%$. Urea is part of the natural moisturizing factor of the epidermis and is known as effective moisturizing and barrier-enhancing active for skin care products [47]. Today, it is commonly accepted, that urea shows a broad effectiveness for dermo-cosmetic products [49] [50] [51]. The present study has shown that the test product A with a content of $10 \%$ urea contributes to the efficacy in case of SC moisturization and improving EPB function as previously reviewed [47]. Since urea is a hygroscopic molecule, it keeps moisture and hydrates the skin. Concerning the barrier-enhancing effects, it was shown that $10 \%$ urea regulates genes, which are involved in keratinocyte differentiation and lipid synthesis [48]. Our present results show, that an acidic o/w emulsion containing $10 \%$ urea has a positive impact on SC hydration, ss-pH and EPB function. Moreover, it was shown, that there are no negative interactions between the acidic product $\mathrm{pH}$ and $10 \%$ urea, regarding product properties and skin compatibility.

\section{Conclusion}

In conclusion, the marketed test product A significantly increased SC hydration, improved the acidic character of the skin and enhanced EPB function, in terms 
of SC integrity, cohesion and recovery to a greater extent compared to the reference product B. Based on the present work, controlling the ss-pH in subjects with xerotic and atopic-prone skin via application of skin care formulation with a lowered $\mathrm{pH}$, like 4.5 , in combination with a $10 \%$ urea concentration is recommended. The results are important for the formulation of topical products for very dry and atopic skin. Using such formulations seems to be a strategy for targeted and direct skin acidification to overcome pathological $\mathrm{pH}$ changes and EPB malfunction in dry and atopic skin. Nevertheless, the present study results are primarily limited to the herewith evaluated marketed product A. This means that a transfer of the shown product effects to other products with similar product characteristics like identical $\mathrm{pH}$ or urea content is not automatically feasible. In addition, the shown effects are limited to the used biophysical parameters, especially concerning skin barrier function, and are not directly linked to the improvement of other dysfunctions in very dry and atopic skin, e.g. inflammatory processes. Moreover, larger clinical long-term trials with additional control conditions are necessary to create more evidence concerning this skin care strategy for atopic dermatitis or subjects with dry skin and atopic diathesis.

\section{Acknowledgements}

The study was initiated and sponsored by the Department of Research \& Development, Kneipp GmbH, Würzburg, Germany. We are grateful to all our volunteers who have given up their time to take part in our study. Both, the test product A (Internal No. NHH081, Kneipp ${ }^{\circledR}$ Evening Primrose Skin Care) and the reference product B (Internal No. GVB154B) were provided by Kneipp. J.B., C.T., M.S., I.S. and P.S. are employees of Kneipp.

\section{Conflicts of Interest}

The authors declare no conflicts of interest regarding the publication of this paper.

\section{References}

[1] Elias, P.M. (2005) Stratum Corneum Defensive Functions: An Integrated View. Journal of Investigative Dermatology, 125, 183-200. https://doi.org/10.1111/j.0022-202X.2005.23668.x

[2] Menon, G.K. and Kligman, A.M. (2009) Barrier Functions of Human Skin: A Holistic View. Skin Pharmacology and Physiology, 22, 178-189. https://doi.org/10.1159/000231523

[3] Bosko, C.A. (2019) Skin Barrier Insights: From Bricks and Mortar to Molecules and Microbes. Journal of Drugs in Dermatology, 18, s63-s67.

[4] Michaels, A.S., Chandrasekaran, S.K. and Shaw, J.E. (1975) Drug Permeation through Human Skin: Theory and in Vitro Experimental Measurement. AIChE Journal, 21, 985-996. https://doi.org/10.1002/aic.690210522

[5] Johnson, M.E., Blankschtein, D. and Langer, R. (1997) Evaluation of Solute Permeation through the Stratum Corneum: Lateral Bilayer Diffusion as the Primary 
Transport Mechanism. Journal of Pharmaceutical Sciences, 86, 1162-1172. https://doi.org/10.1021/js960198e

[6] Proksch, E., Folster-Holst, R. and Jensen, J.M. (2006) Skin Barrier Function, Epidermal Proliferation and Differentiation in Eczema. Journal of Dermatological Science, 43, 159-169. https://doi.org/10.1016/j.jdermsci.2006.06.003

[7] Elias, P.M. and Menon, G.K. (1991) Structural and Lipid Biochemical Correlates of the Epidermal Permeability Barrier. Advances in Lipid Research, 24, 1-26. https://doi.org/10.1016/B978-0-12-024924-4.50005-5

[8] Miajlovic, H., Fallon, P.G., Irvine, A.D. and Foster, T.J. (2010) Effect of Filaggrin Breakdown Products on Growth of and Protein Expression by Staphylococcus aureus. Journal of Allergy and Clinical Immunology, 126, 1184-1190. https://doi.org/10.1016/j.jaci.2010.09.015

[9] Jensen, J.M., Schütze, S., Förl, M., Krönke, M. and Proksch, E. (1999) Roles for Tumor Necrosis Factor Receptor p55 and Sphingomyelinase in Repairing the Cutaneous Permeability Barrier. Journal of Clinical Investigation, 104, 1761-1770. https://doi.org/10.1172/JCI5307

[10] Sanford, J.A. and Gallo, R.L. (2013) Functions of the Skin Microbiota in Health and Disease. Seminars in Immunology, 25, 370-377.

https://doi.org/10.1016/j.smim.2013.09.005

[11] Nakatsuji, T., Chiang, H.I., Jiang, S.B., Nagarajan, H., Zengler, K. and Gallo, R.L. (2013) The Microbiome Extends to Subepidermal Compartments of Normal Skin. Nature Communications, 4, Article No. 1431. https://doi.org/10.1038/ncomms2441

[12] Proksch, E., Brandner, J.M. and Jensen, J.M. (2008) The Skin: An Indispensable Barrier. Clinical and Experimental Dermatology, 17, 1063-1072. https://doi.org/10.1111/j.1600-0625.2008.00786.x

[13] Eberlein-König, B., Schäfer, T., Huss-Marp, J., Darsow, U., Möhrenschlager, M., Herbert, O., Abeck, D., Krämer, U., Behrendt, H. and Ring, J. (2000) Skin Surface pH, Stratum Corneum Hydration, Trans-Epidermal Water Loss and Skin Roughness Related to Atopic Eczema and Skin Dryness in a Population of Primary School Children. Acta Dermato- Venereologica, 80, 188-191. https://doi.org/10.1080/000155500750042943

[14] Seidenari, S. and Giusti, G. (1995) Objective Assessment of the Skin of Children Affected by Atopic Dermatitis: A Study of pH, Capacitance and TEWL in Eczematous and Clinically Uninvolved Skin. Acta Dermato-Venereologica, 75, 429-433.

[15] Seite, S., Flores, G.E., Henley, J.B., Martin, R., Zelenkova, H., Aguilar, L. and Fierer, N. (2014) Microbiome of Affected and Unaffected Skin of Patients with Atopic Dermatitis before and after Emollient Treatment. Journal of Drugs in Dermatology, 13, 611-618.

[16] Fluhr, J.W. and Elias, P.M. (2002) Stratum Corneum pH: Formation and Function of the "Acid Mantle". Exogenous Dermatology, 1, 163-175. https://doi.org/10.1159/000066140

[17] Segger, D., Aßmus, U., Brock, M., Erasmy, J., Finkel, P., Fitzner, A., Heuss, H., Kortemeier, U., Munke, S., Rheinländer, T., Schmidt-Lewerkühne, H. and Schneider, W. and Weser, G. (2007) Multicenter Study on Measurement of the Natural pH of the Skin Surface. IFSCC Magazine, 10, 107-110.

[18] Lambers, H., Piessens, S., Bloem, A., Pronk, H. and Finkel, P. (2006) Natural Skin Surface $\mathrm{pH}$ Is on Average below 5, Which Is Beneficial for Its Resident Flora. International Journal of Cosmetic Science, 28, 359-370. 
https://doi.org/10.1111/j.1467-2494.2006.00344.x

[19] Schade, H. and Marchionini, A. (1928) Der Säuremantel der Haut (nach Gaskettenmessungen). Journal of Molecular Medicine, 7, 12-14.

https://doi.org/10.1007/BF01711684

[20] Choi, E.H., Man, M.Q., Xu, P., Xin, S., Liu, Z., Crumrine, D.A., Jiang, Y.J., Fluhr, J.W., Feingold, K.R., Elias, P.M. and Mauro, T.M. (2007) Stratum Corneum Acidification Is Impaired in Moderately Aged Human and Murine Skin. Journal of Investigative Dermatology, 127, 2847-2856. https://doi.org/10.1038/sj.jid.5700913

[21] Man, M.Q., Xin, S.J., Song, S.P., Cho, S.Y., Zhang, X.J., Tu, C.X., Feingold, K.R. and Elias, P.M. (2009) Variation of Skin Surface pH, Sebum Content and Stratum Corneum Hydration with Age and Gender in a Large Chinese Population. Skin Pharmacology and Physiology, 22, 190-199. https://doi.org/10.1159/000231524

[22] Schreml, S., Zeller, V., Meier, R.J., Korting, H.C., Behm, B., Landthaler, M. and Babilas, P. (2012) Impact of Age and Body Site Adult Female Skin Surface pH. Dermatology, 224, 66-71. https://doi.org/10.1159/000337029

[23] Blaak, J., Wohlfart, R. and Schürer, N.Y. (2011) Treatment of Aged Skin with a pH 4 Skin Care Product Normalizes Increased Skin Surface $\mathrm{pH}$ and Improves Barrier Function: Results of a Pilot Study. Journal of Cosmetics, Dermatological Sciences and Applications, 1, 50-58. https://doi.org/10.4236/jcdsa.2011.13009

[24] Luebberding, S., Krueger, N. and Kerscher, M. (2014) Age-related Changes in Male Skin: Quantitative Evaluation of One Hundred and Fifty Male Subjects. Skin Pharmacology and Physiology, 27, 9-17. https://doi.org/10.1159/000351349

[25] Sparavigna, A., Setaro, M. and Gualandri, V. (1999) Cutaneous pH in Children Affected by Atopic Dermatitis and in Healthy Children: A Multicenter Study. Skin Research and Technology, 5, 221-227. https://doi.org/10.1111/j.1600-0846.1999.tb00134.x

[26] Rippke, F., Schreiner, V. and Schwanitz, H.J. (2002) The Acidic Milieu of the Horny Layer. New Findings on the Physiology and Pathophysiology of Skin pH. American Journal of Clinical Dermatology, 3, 261-272. https://doi.org/10.2165/00128071-200203040-00004

[27] Maibach, H. and Levin, J. (2011) pH Buffering Considerations in Mature Skin. Cosmetics \& Toiletries, 126, 422-428.

[28] Elias, P.M. and Choi, E.H. (2005) Interactions among Stratum Corneum Defensive Functions. Experimental Dermatology, 14, 719-726. https://doi.org/10.1111/j.1600-0625.2005.00363.x

[29] Borgono, C.A., Michael, I.P., Komatsu, N., Jayakumar, A., Kapadia, R., Clayman, G.L., Sotiropoulou, G. and Diamandis, E.P. (2007) A Potential Role for Multiple Tissue Kallikrein Serine Proteases in Epidermal Desquamation. The Journal of Biological Chemistry, 282, 3640-3652. https://doi.org/10.1074/jbc.M607567200

[30] Caubet, C., Jonca, N., Brattsand, M., Guerrin, M., Bernard, D., Schmidt, R., Egelrud, T., Simon, M. and Serre, G. (2004) Degradation of Corneodesmosome Proteins by Two Serine Proteases of the Kallikrein Family, SCTE/KLK5/hK5 and SCCE/KLK7/hK7. Journal of Investigative Dermatology, 122, 1235-1244. https://doi.org/10.1111/j.0022-202X.2004.22512.x

[31] Brattsand, M., Stefansson, K., Lundh, C., Haasum, Y. and Egelrud, T. (2005) A Proteolytic Cascade of Kallikreins in the Stratum Corneum. Journal of Investigative Dermatology, 124, 198-203. https://doi.org/10.1111/j.0022-202X.2004.23547.x

[32] Ovaere, P., Lippens, S., Vandenabeele, P. and Declercq, W. (2009) The Emerging 
Roles of Serine Protease Cascades in the Epidermis. Trends in Biochemical Sciences, 34, 453-463. https://doi.org/10.1016/j.tibs.2009.08.001

[33] Mauro, T., Holleran, W.M., Grayson, S., Gao, W.N., Man, M.Q., Kriehuber, E., Behne, M., Feingold, K.R. and Elias P.M. (1998) Barrier Recovery Is Impeded at Neutral pH, Independent of Ionic Effects: Implications for Extracellular Lipid Processing. Archives of Dermatological Research, 290, 215-222. https://doi.org/10.1007/s004030050293

[34] Holleran, W.M. and Takagi, Y. (2006) Stratum Corneum Lipid Processing: The Final Steps in Barrier Formation. In: Elias, P.M. and Feingold, K.R., Eds., Skin Barrier, Taylor \& Francis, Abingdon, 231-259.

[35] Elias, P.M. and Choi, E.H. (2005) Interactions among Stratum Corneum Defensive Functions. Experimental Dermatology, 14, 719-726. https://doi.org/10.1111/j.1600-0625.2005.00363.x

[36] Blaak, J., Kaup, O., Hoppe, W., Baron-Ruppert, G., Langheim, H., Staib, P., Wohlfart, R., Lüttje, D. and Schürer, N.Y. (2015) A Long-Term Study to Evaluate Acidic Skin Care Treatment in Nursing Home Residents: Impact on Epidermal Barrier Function and Microflora in Aged Skin. Skin Pharmacology and Physiology, 28, 269-279. https://doi.org/10.1159/000437212

[37] Behm, B., Kemper, M., Babilas, P., Abels, C. and Schreml, S. (2015) Impact of a Glycolic Acid-Containing pH 4 Water-in-Oil Emulsion on Skin pH. Skin Pharmacology and Physiology, 28, 290-295. https://doi.org/10.1159/000439030

[38] Blaak, J., Dähnhardt, D., Dähnhardt-Pfeiffer, S., Bielfeldt, S., Wilhelm, K.P., Wohlfart, R. and Staib, P. (2017) A Plant Oil-containing pH 4 Emulsion Improves Epidermal Barrier Structure and Enhances Ceramide Levels in Aged Skin. International Journal of Cosmetic Science, 39, 284-291. https://doi.org/10.1111/ics.12374

[39] Angelova-Fischer, I., Fischer, T.W., Abels, C. and Zillikens, D. (2018) Accelerated Barrier Recovery and Enhancement of the Barrier Integrity and Properties by Topical Application of a pH 4 vs. a pH 5.8 Water-in-Oil Emulsion in Aged Skin. British Journal of Dermatology, 179, 471-477. https://doi.org/10.1111/bjd.16591

[40] Kilic, A., Masur, C., Reich, H., Knie, U., Dähnhardt, D., Dähnhardt-Pfeiffer, S. and Abels, C. (2019) Skin Acidification with a Water-in-Oil Emulsion (pH 4) Restores Disrupted Epidermal Barrier and Improves Structure of Lipid Lamellae in the Elderly. The Journal of Dermatology, 46, 457-465.

https://doi.org/10.1111/1346-8138.14891

[41] Hatano, Y., Man, M.Q., Uchida, Y., Crumrine, D., Scharschmidt, T.C., Kim, E.G., Mauro, T.M., Feingold, K.R., Elias, P.M. and Holleran, W.M. (2009) Maintenance of an Acidic Stratum Corneum Prevents Emergence of Murine Atopic Dermatitis. Journal of Investigative Dermatology, 129, 1824-1835. https://doi.org/10.1038/jid.2008.444

[42] Sakai, T., Hatano, Y., Zhang, W. and Fujiwara, S. (2014) Defective Maintenance of $\mathrm{pH}$ of Stratum Corneum Is Correlated with Preferential Emergence and Exacerbation of Atopic-Dermatitis-Like Dermatitis in Flaky-Tail Mice. Journal of Dermatological Science, 74, 222-228. https://doi.org/10.1016/j.jdermsci.2014.01.012

[43] Lee, H.J., Yoon, N.Y., Lee, N.R., Jung, M., Kim, D.H. and Choi, E.H. (2014) Topical Acidic Cream Prevents the Development of Atopic Dermatitis- and Asthma-Like Lesions in Murine Model. Experimental Dermatology, 23, 736-741. https://doi.org/10.1111/exd.12525

[44] Jang, H., Matsuda, A., Jung, K., Karasawa, K., Matsuda, K., Oida, K., Ishizaka, S., 
Ahn, G., Amagai, Y., Moon, C., Kim, S.H., Arkwright, P.D., Takamori, K., Matsuda, H. and Tanaka A. (2016) Skin pH Is the Master Switch of Kallikrein 5-Mediated Skin Barrier Destruction in a Murine Atopic Dermatitis Model. Journal of Investigative Dermatology, 136, 127-135. https://doi.org/10.1038/JID.2015.363

[45] Panther, D.J. and Jacob, S.E. (2015) The Importance of Acidification in Atopic Eczema: An Underexplored Avenue for Treatment. Journal of Clinical Medicine, 5, 970-978. https://doi.org/10.3390/jcm4050970

[46] Denby, S.G. and Cork, M.J. (2018) pH in Atopic Dermatitis. Current Problems in Dermatology, 54, 95-107. https://doi.org/10.1159/000489523

[47] Loden, M. (2009) Urea as a Moisturizing and Barrier-Enhancing Ingredient. In: Rawlings, A.V. and Leyden, J.J., Eds., Skin Moisturization, Informa Healthcare, London, 335-346. https://doi.org/10.3109/9781420070958.021

[48] Grether-Beck, S., Felsner, I., Brenden, H., Kohne, Z., Majora, M., Marini, A., Jaenicke, T., Rodriguez-Martin, M., Trullas, C., Hupe, M., Elias, P.M. and Krutmann, J. (2012) Urea Uptake Enhances Barrier Function and Antimicrobial Defense in $\mathrm{Hu}$ mans by Regulating Epidermal Gene Expression. Journal of Investigative Dermatology, 132, 1561-1572. https://doi.org/10.1038/jid.2012.42

[49] Celleno, L. (2018) Topical Urea in Skincare: A Review. Dermatologic Therapy, 31, e12690. https://doi.org/10.1111/dth.12690

[50] Scheinfeld, N.S. (2010) Urea: A Review of Scientific and Clinical Data. Skinmed, 8, 102-106.

[51] Pan, M., Heinicke, G., Bernado, S., Tsui, C. and Levitt, J. (2013) Urea: A Comprehensive Review of the Clinical Literature. Dermatology Online Journal, 19, Article ID: 20392

[52] Dähnhardt, D., Surber, C. and Dähnhardt-Pfeiffer, S. (2018) Influence of Topical Formulations: Lipid Lamella Organization and Lipid Composition of Stratum Corneum as a Surrogate Marker for Barrier Integrity. Current Problems in Dermatology, 54, 166-172. https://doi.org/10.1159/000489530

[53] Wohlrab, J. and Gebert, A. (2018) pH and Buffer Capacity of Topical Formulations. Current Problems in Dermatology, 54, 123-131.

https://doi.org/10.1159/000489526

[54] Parra, J.L. and Paye, M. (2003) EEMCO Guidance for the in Vivo Assessment of Skin Surface pH. Skin Pharmacology and Physiology, 16, 188-202. https://doi.org/10.1159/000069756

[55] Rogiers, V. (2001) EEMCO Guidance for the Assessment of Transepidermal Water Loss in Cosmetic Sciences. Skin Pharmacology and Physiology, 14, 117-128. https://doi.org/10.1159/000056341

[56] Berardesca, E. (1997) EEMCO Guidance for the Assessment of Stratum Corneum Hydration: Electrical Methods. Skin Research and Technology, 3, 126-132. https://doi.org/10.1111/j.1600-0846.1997.tb00174.x

[57] Pelc, J., Czarnecka-Operacz, M. and Adamski, Z. (2018) Structure and Function of the Epidermal Barrier in Patients with Atopic Dermatitis-Treatment Options. Part One. Advances in Dermatology and Allergology, 35, 1-5. https://doi.org/10.5114/ada.2018.73159

[58] Bieber, T. (2010) Atopic Dermatitis. Annals of Dermatology, 22, 125-137. https://doi.org/10.5021/ad.2010.22.2.125

[59] Elias, P.M. (2014) Lipid Abnormalities and Lipid-Based Repair Strategies in Atopic Dermatitis. Biochimica et Biophysica Acta, 1841, 323-330. 
https://doi.org/10.1016/j.bbalip.2013.10.001

[60] Dähnhardt-Pfeiffer, S., Surber, C., Wilhelm, K.P., Dähnhardt, D., Springmann, G., Böttcher, M. and Fölster-Holst, R. (2012) Noninvasive Stratum Corneum Sampling and Electron Microscopical Examination of Skin Barrier Integrity: A Pilot Study with a Topical Glycerin Formulation for Atopic Dermatitis. Skin Pharmacology and Physiology, 25, 155-161. https://doi.org/10.1159/000336789

[61] Rawlings, A.V. (2014) Molecular Basis for Stratum Corneum Maturation and Moisturization. British Journal of Dermatology, 171, 19-28.

https://doi.org/10.1111/bjd.13303 